\title{
Calciphylaxis in Man
}

\author{
J. K. H. REES,** M.в., B.S. ; G. A. COLES, $\dagger$ M.B., M.R.C.P.
}

Sum ummary : A patient with renal failure developed widespread calcification in the thighs after the injection of iron-dextran (Imferon). This is considered as an example of calciphylaxis, a process in which calcium is laid down in parts of the body following the administration of a "challenger." Iron-dextran is a known challenger, and should be used with caution in uraemic subjects, who may be sensitized by high serum parathyroid hormone levels. Contributing factors may have been a high calcium/phosphate product, steroids, and the patient's immobility.

\section{Introduction}

The association between renal failure and soft-tissue calcification was first described over 100 years ago by Virchow (1855). Although well recognized, it remains uncommon. The tissues singled out for calcification are the eyes (Perrin, Vantelon, and Zingraff, 1966 ; Berlyne and Shaw, 1967); the heart, kidneys, lungs, stomach, and dura (Smyth and Goldman, 1934; Mulligan, 1947); blood vessels (Albright, Drake, and Sulkowitch, 1937); and skin (Pollack and Siegal, 1935; Magnus and Bodley Scott, 1936). Soft-tissue calcification is more likely to occur in children and young adults (Andersen and Schlesinger, 1942). The local and systemic factors responsible for the deposition of calcium in skin and other sites have been reviewed by Gayler and Brogdon (1965) and by Fourman and Royer (1968).

The case described here illustrates a mechanism of calcification which has received little attention. This process, called calciphylaxis, was first described by Selye (1962a) and defined as "a biologic mechanism through which mineralization can be elicited selectively in limited areas of the body by the administration of 'challengers' during a 'critical period' after sensitization."

\section{Case Report}

The patient was a 21-year-old man who was admitted to the medical unit, Cardiff Royal Infirmary, in September 1967. Ten years earlier a diagnosis of acute glomerulonephritis had been made in another hospital. Recovery was incomplete and in the latter seven years of regular follow-up he was noted to have hypertension and proteinuria.

In August 1967 he was admitted to his local hospital because renal function had deteriorated and high blood pressure had been more difficult to control. Urine output was 2 to 3 litres in 24 hours. He was treated with restricted sodium and protein and hypotensive drugs. He also received nandrolone phenylpropionate (Durabolin) $25 \mathrm{mg}$. weekly by intramuscular injection. He improved sufficiently to be discharged from hospital after two weeks.

On 1 September he was readmitted with nausea, vomiting, headache, and extreme lassitude. Examination of his limbs at this time showed no areas of tenderness or induration. His blood pressure was $180 / 110$ and his blood urea $400 \mathrm{mg} . / 100 \mathrm{ml}$. The urine output, initially 2 litres in 24 hours, decreased after one week to

- Senior House Officer, Royal Infirmary, Cardiff, Glamorgan. Present address: Department of Medicine, Hammersmith Hospital, Ducane Road, London W.12.

t Research Fellow in Medicine, Royal Infirmary, Cardiff, Glamorgan.

Requests for reprints to be sent to: Dr. J. K. H. Rees, Hammersmith Hospital, Ducane Road, London W.12.
1 litre in 24 hours. Haemoglobin level was $7 \cdot 3$ g./ $100 \mathrm{ml}$., with a mild degree of hypochromia. Prednisone $40 \mathrm{mg}$. daily was started, increasing to $60 \mathrm{mg}$, daily for one week and subsequently decreasing to $30 \mathrm{mg}$. daily. The nandrolone phenylpropionate was continued. On 6 September he received a test dose of $2 \mathrm{ml}$. of iron-dextran complex (Imferon), and on each of the next six days $5 \mathrm{ml}$. was injected intramuscularly into the anterolateral aspects of alternate thighs (total $32 \mathrm{ml}$.)

On 14 September, eight days after the first dose, it was noted that the lateral and anterior borders of both thighs around the sites of the injections were tender, discoloured, and swollen. $\mathrm{He}$ was transferred to the care of the medical unit after a further two days.

Clinical State at Time of Transfer.-The patient was pale and thin, and was vomiting and very weak. Blood pressure was 200/120. On the lateral and anterior aspects of the upper third of both thighs there were large hard plaques, which were stained brown-yellow; the staining and induration on the right side extended to the gluteal region and on the left to the medial side of the thigh. The edges of these areas were well demarcated but irregular (Fig. 1). He also had marked band keratopathy.

$X$-ray examination of the thighs showed widespread calcification in the soft tissues (Fig. 2). Histology of a biopsy specimen of a plaque confirmed the presence of calcium deposits in the subcutaneous tissue (Fig. 3).

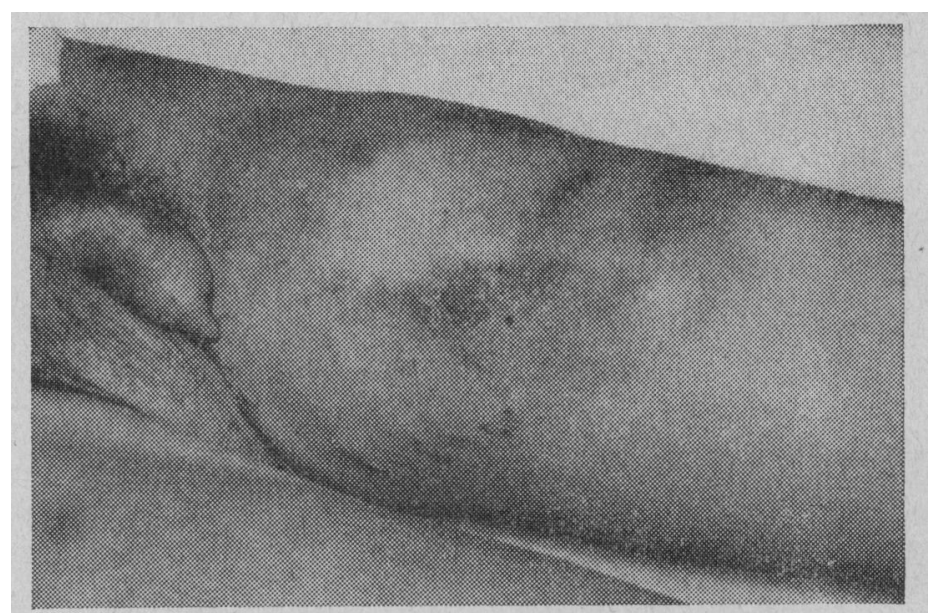

FIG. 1.-Left thigh of patient, showing an area of coloured induration.

Other Investigations.-Serum calcium $7 \cdot 3$ to $8.3 \mathrm{mg} . / 100 \mathrm{ml}$; inorganic phosphate $14.0 \mathrm{mg} . / 100 \mathrm{ml}$. ; calcium/phosphate product $102 \cdot 2$ to $116 \cdot 2$ (normal range $40-55$ ) ; serum total protein $4.4 \mathrm{~g} . /$ $100 \mathrm{ml}$. (albumin $2 \cdot 2 \mathrm{~g} . / 100 \mathrm{ml}$.). Blood urea $570 \mathrm{mg} . / 100 \mathrm{ml}$. ; sodium $125 \mathrm{mEq} / 1$; potassium $4.7 \mathrm{mEq} / 1$. Urinary calcium 3.8 to $5.8 \mathrm{mg} . / 100 \mathrm{ml}$. (40 to $60 \mathrm{mg}$. in 24 hours). Alkaline phosphatase 9 to 14 K.A. units $/ 100 \mathrm{ml}$. Skeletal survey showed no evidence of azotaemic osteodystrophy.

Treatment and Subsequent Course of Illness.-The patient was initially treated with peritoneal dialysis and then with a modified Giovanetti diet (Shaw, Bazzard, Booth, Nilwarangkur, and Berlyne, 1965), blood transfusions, hypotensive drugs, and aluminium hydroxide suspension in a dose of $\frac{1}{2} \mathrm{fl}$. oz. $(14 \mathrm{ml}$.) t.d.s. for four weeks beginning 15 October. Prednisone was rapidly tailed off and stopped. $X$-ray examination of the thighs was repeated after four weeks' treatment with aluminium hydroxide, but no appreciable change in the degree of calcification was found.

After eight weeks his condition remained poor, and at the request of his family he was transferred to his local hospital, where he died a week later. Permission for a necropsy was not sought. 


\section{Discussion}

Selye (1962a) defines calciphylaxis as a biological process in which selective calcification may be produced experimentally in areas of the body of a "sensitized" animal by the administration of a " challenger."

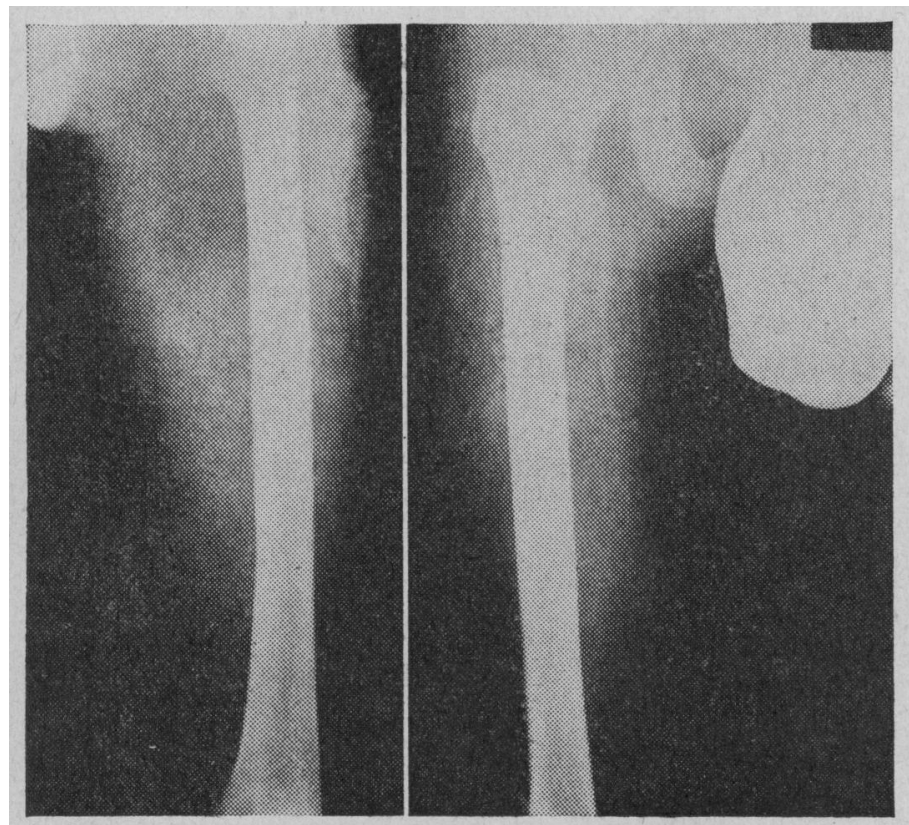

FIG. 2.-Radiographs of thighs, showing extensive calcification in subcutaneous tissues.

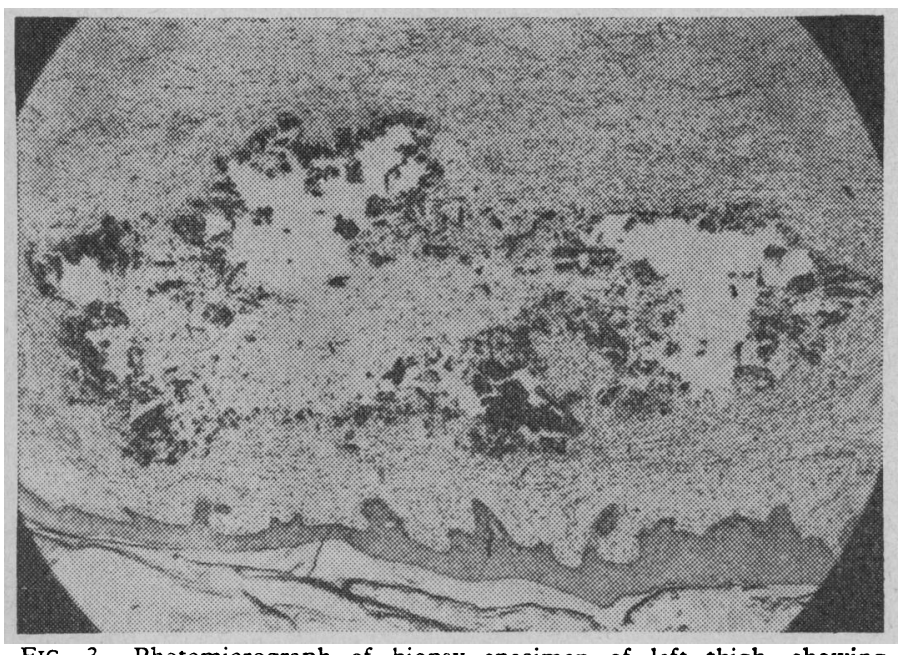

FIG. 3.-Photomicrograph of biopsy specimen of left thigh, showing extensive calcium deposition in subcutaneous tissue. (von Kossa stain.)

Sensitization may be produced by dihydrotachysterol, vitamin-D derivatives, or parathyroid extract (Para-thor-mone). Many challengers were investigated by Selye, but one of the most potent was the iron-dextran compound (Fedex). We believe that the mechanism of calcification taking place in the thighs of our patient is a direct parallel to the experimental calcification produced by Selye (personal communication, 1968). The experiments with rats, in which parathyroid extract was the sensitizing agent and iron-dextran the challenger, are directly comparable to the situation in our patient, where parathyroid extract was the sensitizer and iron-dextran again the challenger.

Although there was no radiological evidence of hyperparathyroidism in our patient, the calcium phosphate product was in the range found by Stanbury and Lumb (1966) in patients with definite evidence of azotaemic hyperparathyroidism. Moreover, in patients with severe chronic renal failure the concentration of parathyroid extract in the blood is commonly raised (Berson and Yalow, 1966).

Calcification may occur at sites of tissue trauma in patients with normal renal function and calcium metabolism. However, there is little evidence of any pathological change at the site of iron injection (Baker, Golberg, Martin, and Smith, 1961). Selye (1962b) found that calcification preceded histologically demonstrable tissue damage in those animals given a challenger after sensitization. The speed with which calcification takes place in calciphylaxis is characteristically rapid (Selye, 1962a). This feature was clearly shown in our patient radiologically within five days of completing the injection of iron-dextran.

Steroids suppress the "reactive phase" of iron absorption from the site of injection (Golberg, 1958). This phase is dependent on a satisfactory inflammatory reaction, which is decreased by steroid therapy. This factor, combined with immobility, may have increased the calciphylactic potential of this compound in our patient. There is no evidence, however, that steroids have a direct potentiating effect on calciphylaxis ; only their suppressive effect on inflammatory response, and therefore on iron absorption, may be implicated in this case. Selye et al. (1964) postulated that the inhibition of calcification in rats put under stress may be due to increased glucocorticoid production, and in this respect may have a distinct protective effect against calciphylaxis. Anabolic steroids may prevent calciphylaxis, but the one used in this instance was ineffective experimentally (Selye, Tuchweber, and Jacqmin, 1965).

Other factors may have contributed to the deposition of calcium in our patient. Berlyne (1968) has drawn attention to the importance of the calcium/phosphate product in the production of conjunctival calcification. It was more likely to occur if the product exceeded 70 . The most important factor in the product was the phosphate level, for the majority of his patients had normal or low values of serum calcium.

There are two accounts of calciphylaxis in uraemic patients ; deposition of calcium was reversed by treatment with a low phosphate diet and aluminium hydroxide gel (Eisenberg and Bartholow, 1963 ; Anderson, Stewart, and Piercy 1968). Aluminium hydroxide did not improve our patient, but it may not have been given for a sufficiently long period.

In uraemic patients, who may be "sensitized" by the higher levels of parathyroid extract produced, the administration of "challengers" like iron-dextran should be undertaken with some caution and with an awareness of the potent quality which it possesses of producing calciphylaxis.

We would like to thank Professor H. Scarborough for permission to publish details of the patient who was under his care and for helpful criticism ; Dr. Hans Selye for helpful discussion ; and Miss Deirdre Thompson and Miss Elizabeth Townsend for help with references and typescript.

\section{REFERENCES}

Albright, F, Drake, T. G., and Sulkowitch, H. W. (1937). Bulletin of the Fohns Hopkins Hospital, 60, 377.

Andersen, D. H., and Schlesinger, E. R. (1942). American fournal of Diseases of Children, 63, 102 .

Anderson, D. C., Stewart, W. K., and Piercy, D. M. (1968). Lancet, 2, 323.

Baker, S. B. de C., Golberg, L., Martin, L. E., and Smith, J. P. (1961). fournal of Pathology and Bacteriology, 82, 453.

Berlyne, G. M. (1968). Lancet, 2, 366.

Berlyne, G. M., and Shaw, A. B. (1967). Lancet, 1, 4.

Berson, S. A., and Yalow, R. S. (1966). Science, 154, 907.

Eisenberg, E., and Bartholow, P. V. (1963). New England fournal of Medicine, 268, 1216.

Fourman, P., and Royer, P. (1968). Calcium Metabolism and the Bone, 2nd ed. Oxford, Blackwell Scientific Publications.

Gayler, B. W., and Brogdon, B. G. (1965). American fournal of Medical Science, 249, 590. 
Golberg, L. (1958). Iron in Clinical Medicine. Berkeley, University of California Press.

Magnus, H. A., and Scott, R. B. (1936). Fournal of Pathology and Bacteriology, 42, 665 .

Mulligan, R. M. (1947). Archives of Pathology, 43, 177.

Perrin, D., Vantelon, J., and Zingraff, J. (1966). Annales d'Oculistique, 199, 771 . Pollack, H., and Siegal, S. (1935). Fournal of the Mount Sinai Hospital,
2, 270.

Selye, H. (1962a). Calciphylaxis. Chicago, University of Chicago Press. Selye, H. (1962b). Fournal of Investigative Dermatology, 39, 259.
Selye, H., Tuchweber, B., and Gabbiani, G. (1964). Acia Endocrinologica, Suppl. No. 90 , p. 203.

Selye, H., Tuchweber, B., and Jacqmin, M. (1965). Acta Endocrinologica, 49, 589.

Shaw, A. B., Bazzard, F. J., Booth, E. M., Nilwarangkur, S., and Berlyne, G. M. (1965)

Smyth, F. S. and Goldman, L. (1934). American fournal of Diseases of Children, 48, 596.

Stanbury, S. W., and Lumb, G. A. (1966). Quarterly founnal of Medicine, 35,1

Virchow, R. (1855). Virchows Archiv für pathologische Aratomie und Physiologie, 8, 103 .

\title{
Tuberous Sclerosis and Cardiac Arrhythmia in Three Zulu Patients
}

\author{
J. E. COSNETT,* M.D., B.SC., M.R.C.P. ; B. H. GIBB, † M.B., M.R.C.P.ED., M.R.C.P.GLASG.
}

\begin{abstract}
Summary : Cardiac arrhythmias, in the form of multiple atrial or ventricular extrasystoles together with various types of conduction defect, occurred in three Zulu patients with tuberous sclerosis. Probably this association occurs more often than has been suspected.
\end{abstract}

\section{Introduction}

A case of tuberous sclerosis reported by Taylor (1968) emphasized the rarity of association between this disease and cardiac arrhythmias. A computer-based literature retrieval search involving " 385,000 articles in 2,500 journals in 28 languages" had yielded no report of the association in the previous three years. During a period of four months at Edendale Hospital we have seen three Zulu patients with features of tuberous sclerosis and associated with cardiac arrhythmia which was otherwise unexplained.

\section{Case 1}

A 21-year-old woman, 34-weeks pregnant, was referred from the antenatal clinic because she was found to have an irregular pulse. Apart from complaints of mild dyspnoea on exertion and of palpitations, there were no symptoms.

She had the typical facial appearance of adenoma sebaceum (Fig. 1). Apart from multiple extrasystoles the heart and cardio-

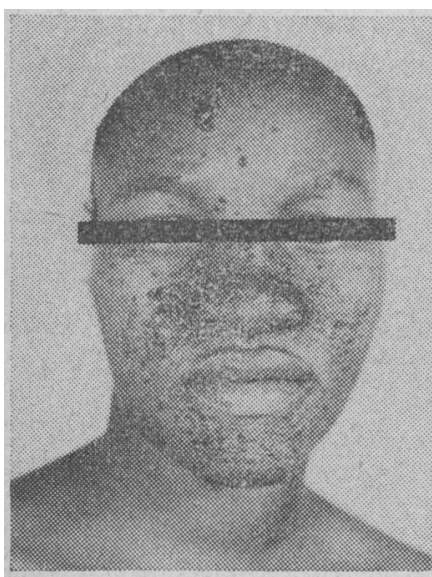

FIG. 1.-Case 1 .

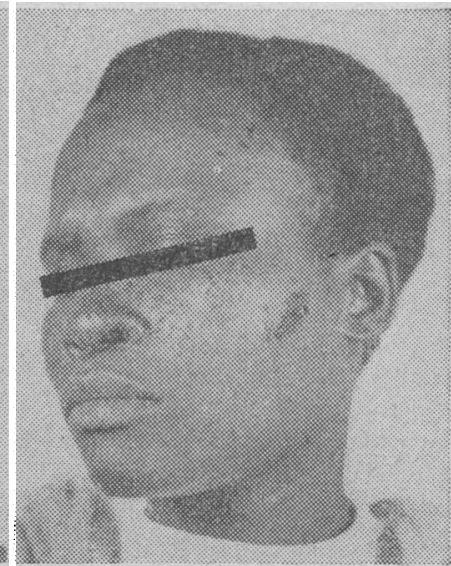

FIG. 3.-Case 2.

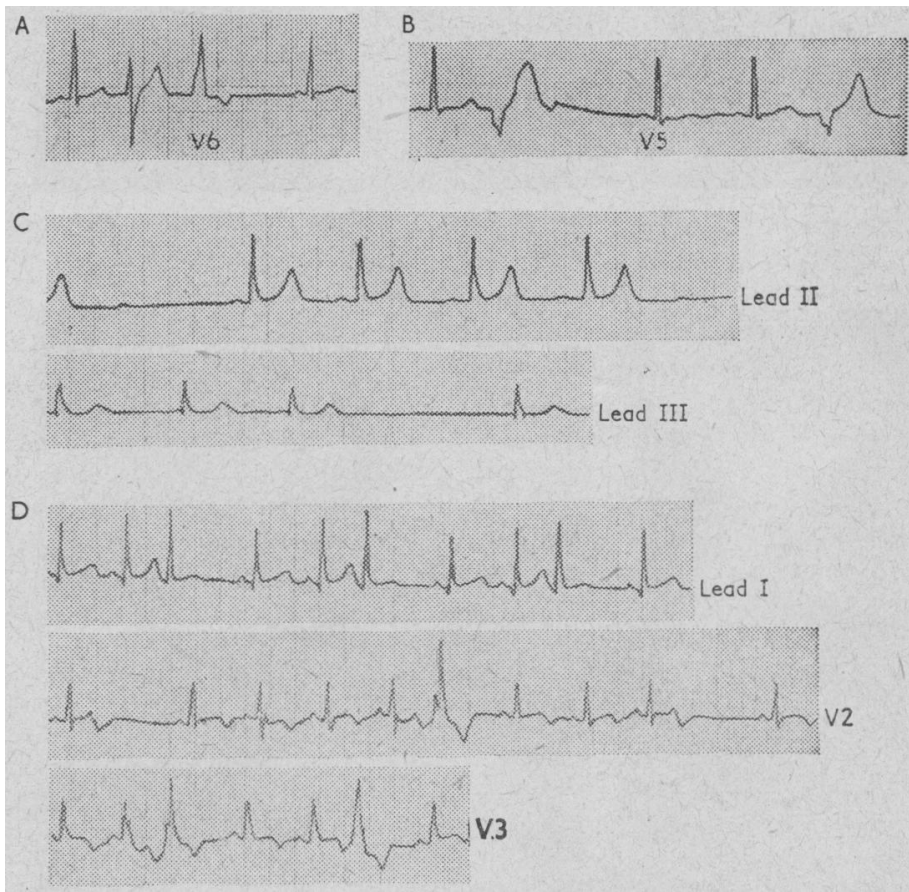

Fig. 2.-Electrocardingrams: A and B, Case 1; C, Case $2 ; \mathrm{D}$, Case 3.

vascular system appeared normal. A crescentic streak of opaque nerve fibres in the right ocular fundus was present, whereas the left fundus was normal. She was of average intelligence, and no apparent abnormality was present in the nervous system. $X$-ray pictures of the chest and skull were also normal. The E.C.G. showed multiple multifocal ventricular extrasystoles (Fig. 2A), which persisted in several subsequent recordings (Fig. 2 B).

On further questioning, the patient told of epileptic fits, whicit had occurred between the ages of 4 and 8 years and had ceased spontaneously. The facial lesions had appeared at about 12 year: of age, and had since become darker and more obvious. She had one previous pregnancy. This baby had appeared normal at birth, but after the first month had begun having fits, which became more frequent until they were occurring two or three times a day. At the age of 6 months the baby had died at home following a succession of fits. Neither of the patient's parents nor any of hei

* Principal Physician, Edendale Hospital, Pietermaritzburg, Natal, Soutb Africa. † Visiting Physician, Edendale Hospital. 